\title{
PERFORMANCE ANALYSIS OF A NEURAL FLUX OBSERVER FOR A BEARINGLESS INDUCTION MACHINE WITH DIVIDED WINDINGS
}

\author{
J. A. Paiva ${ }^{1}$, V. F. Victor ${ }^{2}$, O. S. Andres ${ }^{3}$, A. L. Maitelli ${ }^{3}$ \\ ${ }^{1}$ Dept. of Inf. Tech., Federal Inst. of Education, Science and Technology of Rio G do Norte, Natal, RN, 59015-000, Brazil. \\ ${ }^{2}$ Coord. of Ind. Area, Federal Instit. of Education, Science and Technology of Tocantins, Palmas, TO, 77021-90, Brazil \\ ${ }^{3}$ Dept. of Computing Eng. and Automation, Federal University of Rio G do Norte, Natal, R.N, 59072-970, Brazil. \\ e-mail: josealvaro@ifrn.edu.br, victor@ifto.edu.br, andres@dca.ufrn.br, maitelli@dca.ufrn.br
}

\begin{abstract}
This article presents a system of vector speed control using neural estimation of rotor flux for a 1.1 kWatt winding bearingless three-phase induction machine. The neural estimator is composed of two multilayer feedforward linear networks and substitutes the estimator based on the inverse model of the machine, in which undesirable characteristics such as non-linearity and parametric variations that generate flux estimation errors are observed. The inputs of the developed networks are the currents in vector coordinates of the rotor flux and the mechanical speed of the machine, and their outputs are the angular speed of the rotor flux and the magnetization current. The vector controller operates in conjunction with radial position and current controllers. The control algorithm is implemented in a Digital Signal Processing (DSP) with six PWM monophasic inverters at $10 \mathrm{kHz}$ switch frequency.
\end{abstract}

Keywords - Bearingless machine, DSP, flux estimation, Induction machine, neural network, vector control.

\section{INTRODUCTION}

The study of strategies for controlling electric machines has evolved considerably in recent years. Among the machines under study and applied in large scale is the induction machine, which, because of its low cost and high performance, has become one of the most widely used machines in industry. However, one of the major limitations to widening the application of induction machines is the amount of maintenance required on mechanical parts such as bearings, when access to these parts is difficult.

To minimize mechanical wear and, consequently maintenance, have been proposed induction machines with magnetic bearings and bearingless induction machines [1,2], Figure 1(a) and 1(b) respectively. Comparing the two types of machines, the bearingless induction machine show reduced space, resulting in significantly lower cost.

The bearingless induction machines use magnetic levitation of the rotor to substitute conventional bearings $[2,3]$. The levitating effect is obtained by controlling currents in the stator windings of the machine. Research in this area have been carried out at least two decades, some techniques have been tested $[4,5,6]$. This work contributes in an original

Manuscript received on 07/07/2009. Revised on 08/01/2010 and 17/04/10. Accepted for publication on 17/04/2010 by recommendation of the Editor Fernando L. M. Antunes. way with satisfactory results using a neural observer flux applied to the induction machine without bearings.

One of the most widely known constructive bearingless machine models is the one with a dual stator two-pole winding to control radial positioning and another four-pole winding to control rotational speed [7]. This constructive model has obtained good positioning and torque responses. However, since it is a special dual winding induction machine, its design and construction may be too expensive for large scale applications.

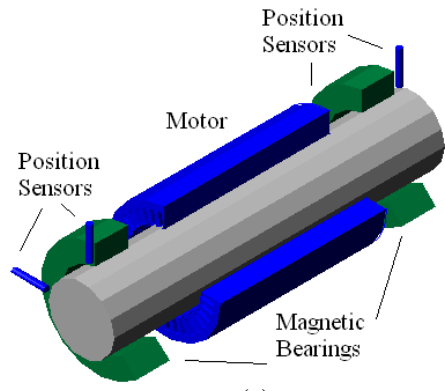

(a)

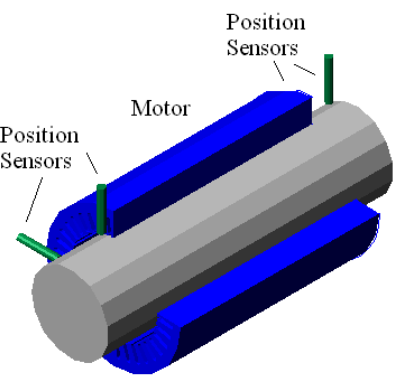

(b)
Fig. 1. (a) Machine with magnetic bearings, (b) Bearingless machine.

Another constructive machine model proposed is a winding bearingless induction machine [8]. This model uses the same structure as conventional machine stators, whose robustness and low cost facilitate its design, making production feasible $[9,10]$. Its winding is split into two coils per phase and it uses only a single coil to control speed and positioning.

The main difference in the structure of bearingless induction machines is in the rotor used. Unlike cage rotors, it is manufactured with coils in closed circuits using an optimized four-pole scheme, whose function is to keep the machine operating at large radial forces supplied by the minimal influence of induced currents and of torque variations in the control of radial position $[11,12]$.

In general to control induction machines, vector techniques stand out for exhibiting good performance in both the transitory and permanent regime. The vector control techniques propose approximating the mathematical model of the induction machine to the model of a continuous current machine [13]. This approximation enables the independent control of flux and torque, which simplifies the structure and controller adjustment.

These vector control strategies show rapid and efficient responses when the machine parameters are precisely known. 
However, due to the difficulty in obtaining these parameters, flux estimation may be compromised, along with the overall performance of the control system.

Another problem in the use of estimators based on fixed parameter models is the non-linearity inherent to the mathematic model of the induction machine, which makes its control relatively complex.

To resolve the problems inherent to estimators based on inverse models with fixed parameters, different types of nonlinear estimators have been proposed. Among these are neural estimators [14], which use learning capacities and adaptability to parametric variations and to the non-linearity of the plans to which they are applied $[15,16,17]$.

In this study the control of rotational speed for winding bearingless three-phase induction machines using neural estimation of rotor flux $[18,19,20]$ combining the advantages of the vector control techniques for machines [21] and for neural networks applied to system estimation.

To perform digital control of rotational speed and radial position, the system uses DSP (Digital Signal Processor), since it is a microcontroller device that exhibits high processing capacity and low cost [22]. Simultaneously to vector control of speed, current and radial position control were also performed [23].

The DSP used operates with 32 bits at $150 \mathrm{MHz}$, enabling communication with a PC via parallel interfaces and RS-232 serial port, in addition to featuring resources such as Analogue/Digital and Digital/Analogue conversion channels and PWM channels to activate the six monophasic inverters that feed the machine.

The control system proposed is applied to a $1.1 \mathrm{~kW}$ horizontal four-pole bearingless induction machine. The control program was developed in standard ANSI C language using its own environment, in which conventional PI controllers (proportional-integrative) were implemented to control the current and PD (proportional-derivative) controllers to control the radial position.

\section{BEARINGLESS MACHINE WITH DIVIDED WINDINGS}

The stator of the induction machine used has divided windings, as shown in Figure 2. The windings were connected in double-star.

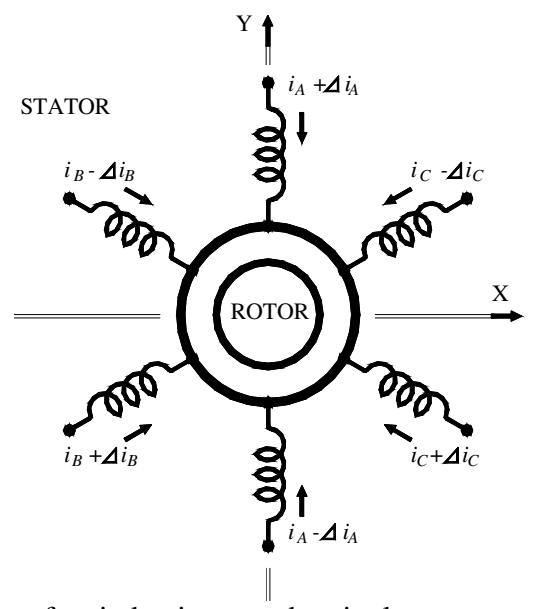

Fig. 2. Stator of an induction-type bearingless motor with divided windings.
The cage rotor used in the machine is manufactured with coils in closed circuits using an optimized four-pole scheme to perform better in controlling radial positioning and speed control [11]. The currents applied to each half-winding are given by:

$$
\begin{aligned}
& i_{A 1}=i_{A}+\Delta i_{A} \\
& i_{A 2}=i_{A}-\Delta i_{A} \\
& i_{B 1}=i_{B}+\Delta i_{B} \\
& i_{B 2}=i_{B}-\Delta i_{B} \\
& i_{C 1}=i_{C}+\Delta i_{C} \\
& i_{C 2}=i_{C}-\Delta i_{C}
\end{aligned}
$$

\section{FLUX MODEL}

The implemented system is based on the control vector technique that controls the induction machine similar to the direct control of the machine's current [12,24].

The use of conventional vector model of induction machines in the study of the bearingless induction machine with divided windings only was possible due to the similarity between their stators structures. These similarities make equivalent both models [10] allowing the implementation of the speed and radial positioning controllers.

The estimation of rotor variables was carried out using the rotor flux frame of reference, since it significantly simplifies the implementation of the digital system. The state equations of the rotor flux are presented below:

$$
\begin{aligned}
& \frac{d i_{m R}}{d t}=\frac{i_{s d}}{\tau_{R}}-\frac{i_{m R}}{\tau_{R}} \\
& \frac{d \rho}{d t}=p . \omega_{m e c}+\frac{i_{s q}}{\tau_{R} i_{m R}} \\
& T_{M}=k \cdot i_{m R} i_{s q} \\
& \tau_{R}=\frac{L_{R}}{R_{R}} \\
& k=\frac{2}{3}(1-\sigma) L_{S}
\end{aligned}
$$

$\begin{array}{cl}\text { Where: } & \\ i_{m R} & \text { - Magnetization current. } \\ i_{S d} & \text { - Field current. } \\ i_{S q} & \text { - Current torque. } \\ \rho & \text { - Rotor flux position. } \\ T_{M} & \text { - Electric torque. } \\ p & \text { - Pole pair number. } \\ \omega_{m e c} & \text { - Mechanical rotor speed. } \\ \tau_{R} & \text { - Rotor time constant. } \\ R_{R} & \text { - Rotor resistance. } \\ L_{R} & \text { - Rotor inductance. } \\ L_{s \cdot} . & \text { - Stator inductance. } \\ \sigma & \text { - Scattering factor. }\end{array}$

The model is non-linear and dependent on the machine parameters. Performance limitations arise mainly from inaccurate knowledge of these parameters or from the influence of external agents such as temperature or flux saturation [12,24]. If parameter variation occurs, the 
estimation of rotor flux will display an error that will influence overall system performance.

This study analyzes the performance of neural flux observer composed of two feedforward neural networks [25] to counterbalance the limitations of the observer. The neural networks simultaneously estimate flux speed and magnetization current that define the rotor flux position (after integrating flux speed) and rotor flux magnitude, respectively.

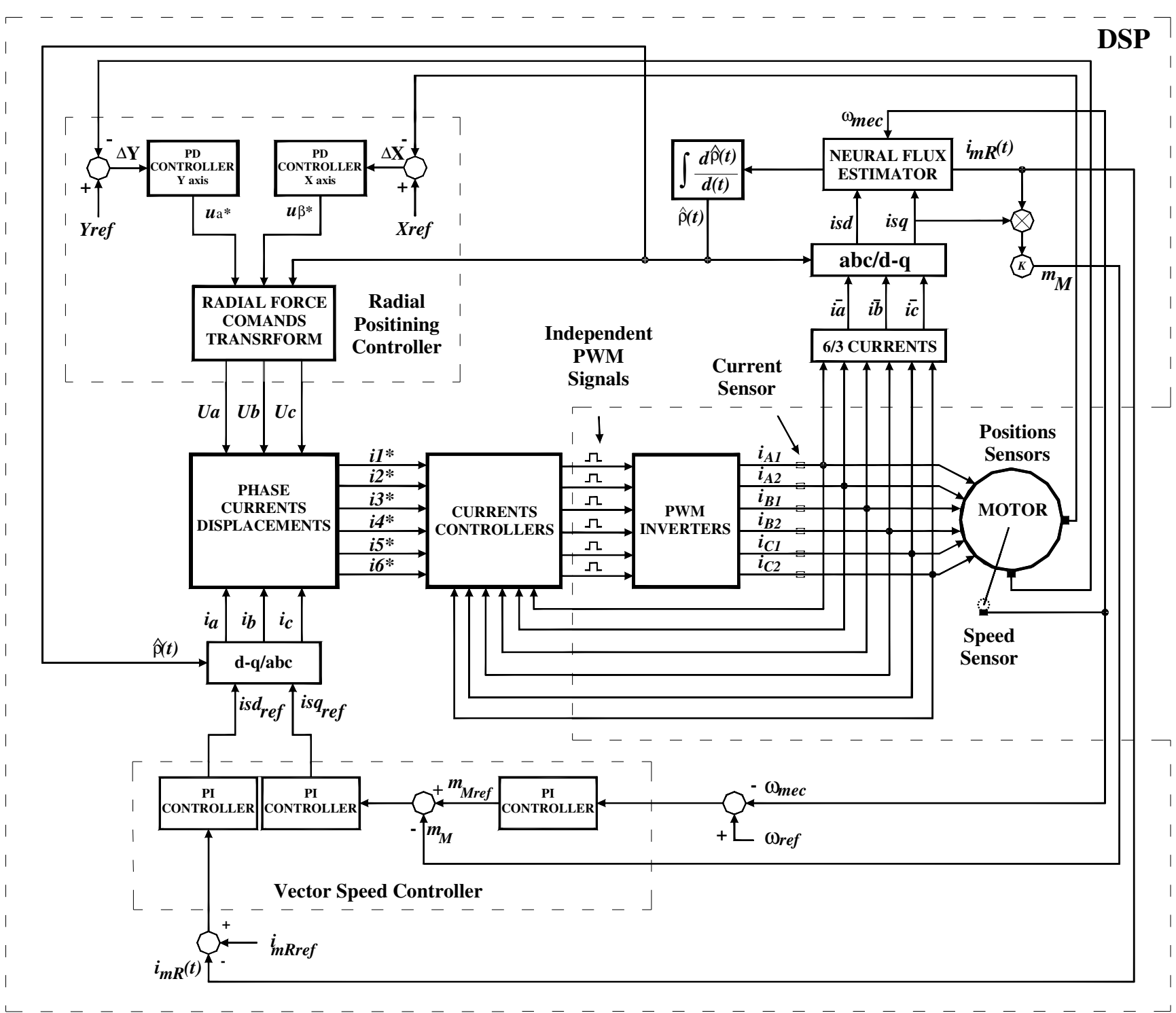

Fig. 3. The complete control system.

\section{IMPLEMENTATION OF THE DIGITAL CONTROL SYSTEM}

The block diagram of the control system is showed in Figure 3. This diagram presents the vector speed controller, the radial positioning controller, the stator current controller and the neural flux estimation. All are implemented in DSP.

The vector speed controller is composed of three PI controllers of the type (Proportional-Integral) digital. Two of these drivers operate in series and are responsible, respectively, for controls speed and torque. His actions have as outputs, the torque reference $m_{M r e f}$ and torque current $i_{\text {Sqref }}$. The third controller performs the control of the magnetizing current, which is responsible for generating the field current $i_{\text {Sdref. }}$
The tuning of speed controllers and torque was performed independently of the driver of the magnetizing current. The mechanical speed read by an optical sensor. During the operation of the motor the sensor generates square pulses and from the count of these pulses is calculated mechanical speed.

The positioning control works based on rotor position measurements performed by two sensors that are arranged in an orthogonal way, where each one reads toward one of the axis. The sensors send the information to the DSP that, based on reference values, generates the six sinusoidal control signals. These signs will be the references for the current controllers.

Analyzing the position measurement $\mathrm{X}$ and $\mathrm{Y}$ from the position sensors is obtained a position error value comparing 
with reference values. This error value is PD position control input that outputs the current variation $\Delta i$ necessary to rotor positioning. It is necessary independent information for each axe ( $\mathrm{X}$ e $\mathrm{Y}$ ), so it is used two controllers. The current variation that locates correctly the rotor in axe $\mathrm{X}$ is done by phase A which receive two different signs, one that supplies half winding plus the current variation $(i+\Delta i)$ and another that supplies the other half winding minus the same current variation $(i-\Delta i)$. A half winding amplifies the torque proportional to increase $\Delta i$ and the other half winding reduce it in the same ratio, so it is reached to keep the same torque.

The current control was implemented digital controllers six identical type Proportional-Integrative (PI), one for each stator coil. These drivers use the current reference $\left(i 1^{*}, i 2^{*}\right.$ $\left.i 3^{*}, i 4^{*}, i 5^{*}, i 6^{*}\right)$ generated by the controlling speed and radial position which is compared with the current read directly from the current sensors $\left(i_{A 1}, i_{A 2}, i_{B 1}, i_{B 2}, i_{C 1}, i_{C 2}\right)$, and their errors are digitally processed by the DSP.

The outputs of the DSP are signs of the type PWM (Pulse With Modulation) modulated by signals from the current controllers. Finally, the PWM signals are applied to threephase inverters that feed the individual stator coils.

The inverters are drive by a voltage power supplied with a current feedback loop, the controllers are implemented in DSP.

The neural flux observer guides the speed vector and rotor positioning control. The six resulting reference components shown in equations 6-11 are applied to the current controller. Finally, the current controller outputs are applied to the six independent winding of bearingless machine.

\section{A. Neural Flux Observer}

The rotor flux observer, necessary to field oriented control, is given by two perceptron multilayer neural networks with the topology shown in Figures 4 (a) and 4 (b). This topology was chosen after several performance tests with different numbers of layers and neurons per layer.

One of the neural network performs the estimation of angular speed $(d \rho(t) / d t)$ and the other performs the estimation of the magnetization current $i_{m R}(t)$.

To minimize the processing time of the DSP neural networks were used linear activation functions. During the tests, it was possible to observe that errors of estimation with this function type were negligible.

The networks training was achieved with the off-line back propagation algorithm using the Toolbox Nntool Matlab® environment. For this, simulations were performed with the equations of the conventional model of the induction machine operating in open loop. The machine parameters used in the training were measured in the laboratory. After networks training, the weights were normalized to operate at a fixed point on the DSP LF2812 [26].

During the training process, were applied variations of \pm $20 \%, 30 \%, 50 \%$ of the nominal value of the constant $\tau_{R}\left(L_{R} /\right.$ $R_{R}$ ) together with changes in frequency of feeding the machine with the objective of training the network for different situations operation of the machine. Thus, if occurring parametric variations due to temperature changes or due to magnetic saturation of the rotor, the network will adapt to every situation, unlike the observer conventional operating with fixed parameters.

Additionally, the conventional flux observer was implemented to provide characteristic comparisons with the neural observer under identical conditions.

The tests conducted with observers neural and conventional were performed under the same conditions of reference of speed and axis load in order to establish a direct comparison between them. For this, the parameters of speed controllers, radial position and current were kept equal to work with each of the observers.

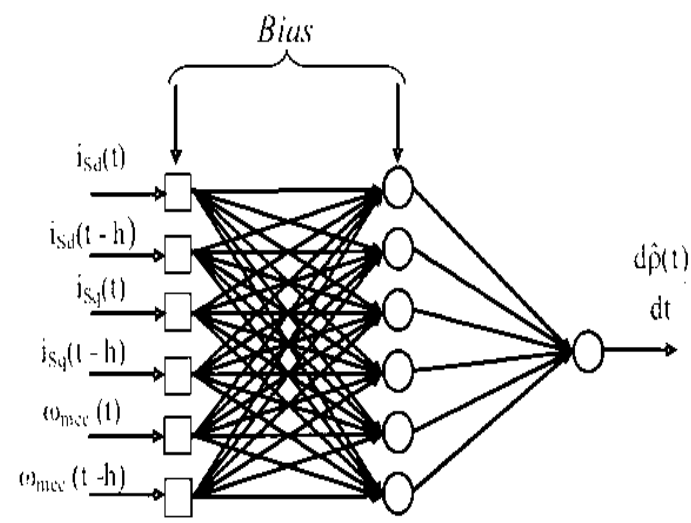

(a)

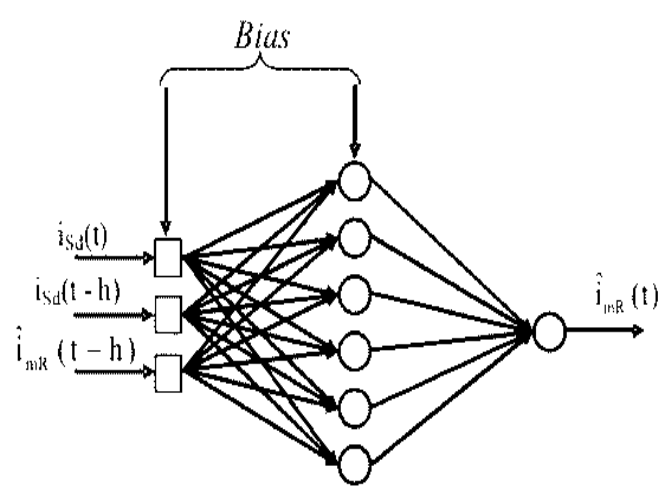

(b)

Fig. 4. Topology of the implemented neural networks of the rotor flux speed (a) and the magnetization current (b).

\section{EXPERIMENTAL RESULTS}

Figure 5 shows the photo of the $1.1 \mathrm{~kW}$ laboratory prototype.

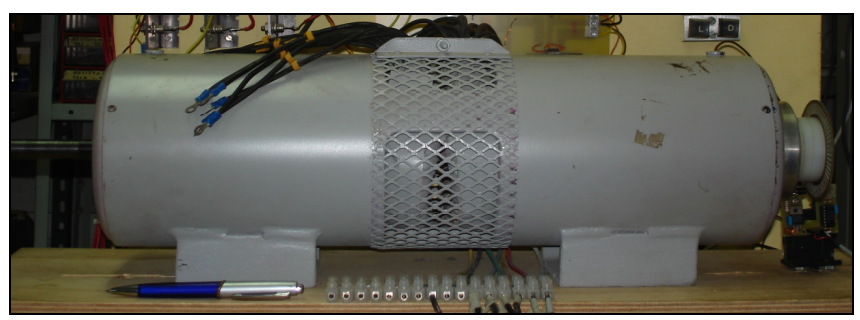

Fig. 5. Laboratory prototype.

The machine parameters were measured in laboratory, and their values are: nominal power $1,1, \mathrm{~kW}$, nominal speed $\omega_{\text {nom }}$ $=1800 \mathrm{rpm}$, nominal voltage $V_{\text {nom }}=220 \mathrm{~V}$, nominal current 
$I_{\text {nom }}=1 \mathrm{~A}$, stator resistance $R_{S}=4.5853 \Omega$, rotor resistance $R_{R}=32.0894 \Omega$, stator and rotor inductance $L_{S}=L_{R}=459.6 \mathrm{mH}$, magnetization inductance $L_{M}=278.6 \mathrm{mH}$, pole par number $p=2$, inertia moment $J=6.06 .10^{-3} \mathrm{~kg} . \mathrm{m}^{2}$ and scattering factor $\sigma=0.1$ flux observer [9] under different test conditions: step, ramp and disturbance responses.

The system performance described in the previous section was compared to that obtained with an inverse model of the flux observer [9] under different test conditions.

\section{A. Step Response}

Initially, with the bearingless motor and no shutdown ( $\mathrm{x}=$ $0.0 \mathrm{~mm}, \mathrm{y}=-0.5 \mathrm{~mm}$ ), the reference speed was changed to $1800 \mathrm{rpm}$. The step response is shown in Figure 6. The positioning obtained with the neural observer is less oscillating. The speed and radial position responses show in Figure 6 presents a slow dynamics due to high inertia displayed by the machine operating in a horizontal position. This limitation can be significantly reduced with the use of the machine in upright position.
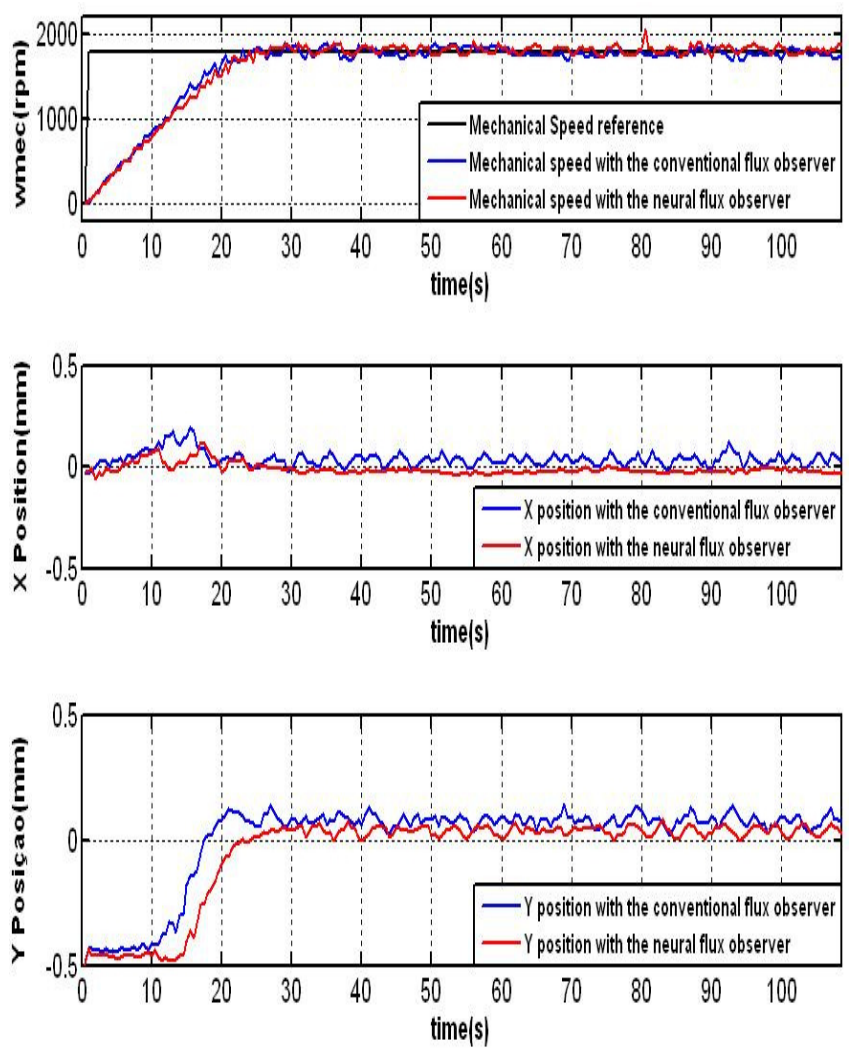

Fig. 6. Step response to mechanical speed and positions $\mathrm{X}$ and $\mathrm{Y}$.

The components $i_{S d}$ and $i_{S q}$ show low oscillation, as can be seen in Figure 7. These components are directly responsible for generating electric torque and one of the main characteristics of this type of machine is the strong dependence of radial positioning with respect to electric torque in each pathway. If electric torque is oscillatory, there will be a significant deterioration of radial positioning control.
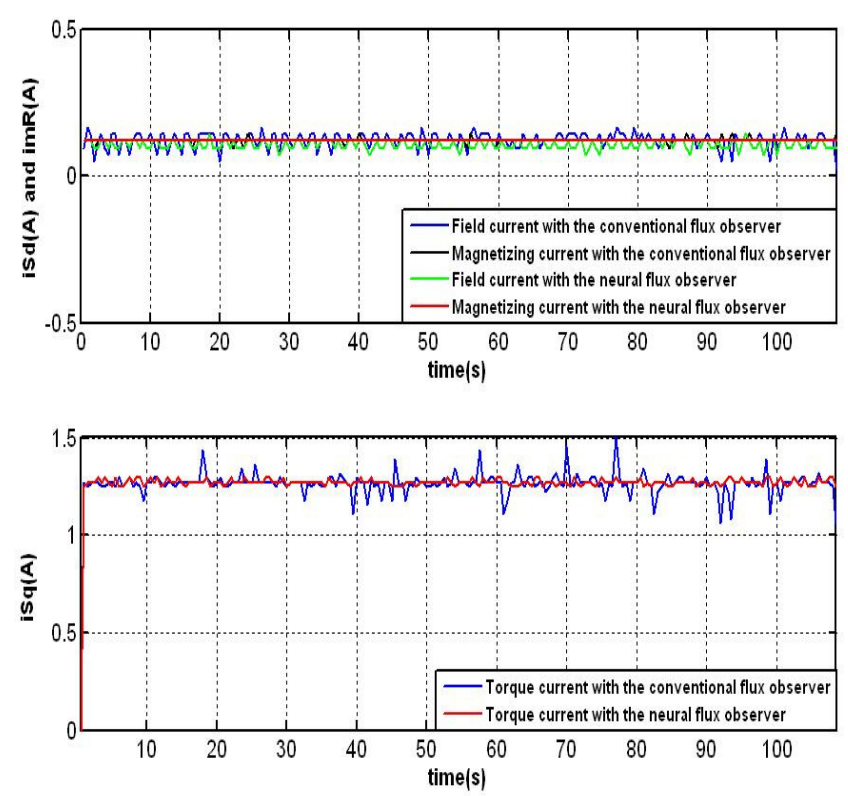

Fig. 7. Field current $\left(i_{S d}\right)$, magnetization current $\left(i_{m R}\right)$ and current torque $\left(i_{S q}\right)$ for a step change.

Analysis of the positioning diagram shown in Figure 8 confirms that the oscillatory torque generated by the control system under the guidance of the conventional observer results in oscillatory positioning control. In addition, positioning errors $\mathrm{X}-\mathrm{Y}$ in the stationary state are greater than the radial positioning errors guided by the neural observer.

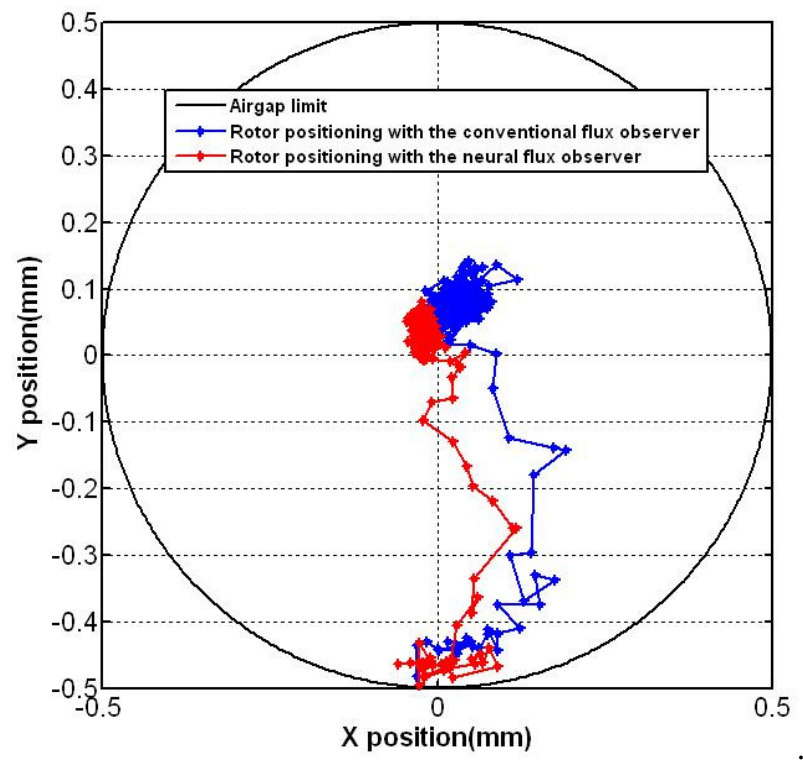

Fig. 8. Diagram of radial positioning with the conventional observer and the neural flux observer for step change.

\section{B. Ramp Response}

Ramp tests were thus conducted. Figure 9 shows that mechanical speed and the X-Y position of the system operating with the neural observer was faster than the same test for the system guided by conventional flux observer errors. 

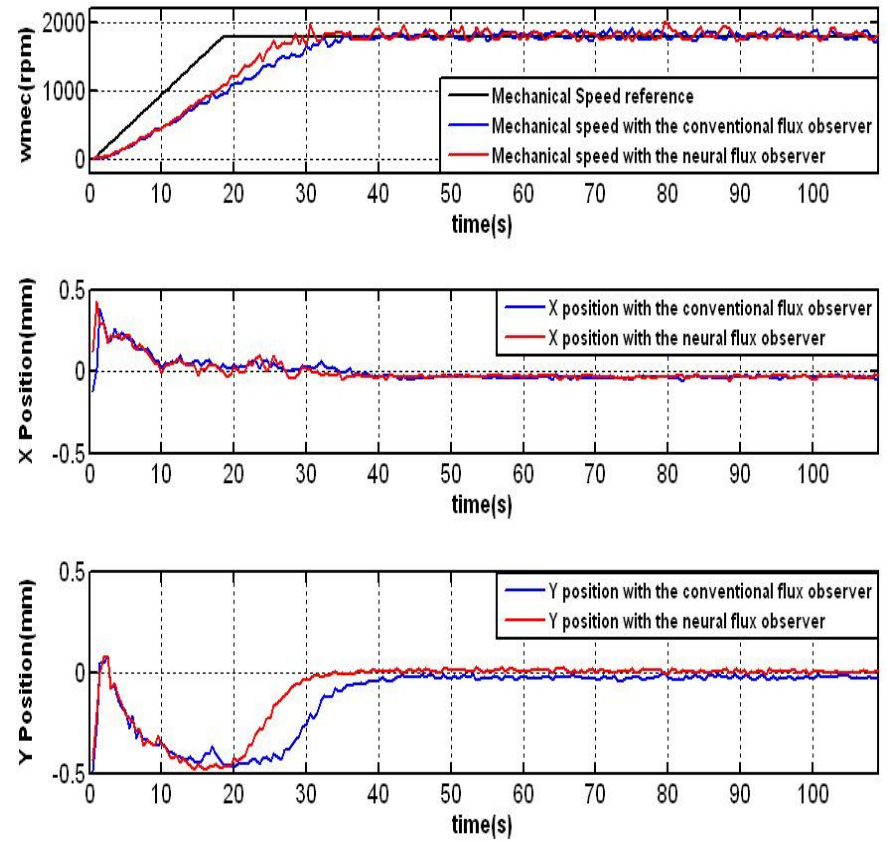

Fig. 9. Response to mechanical speed ramp and to position X and $\mathrm{Y}$.

The current components $i_{S d}$ and $i_{S q}$ shown in Figure 10 maintains the oscillation presented in graph of Figure 7 for the system guided by the conventional observer compared to the system guided by the neural observer.
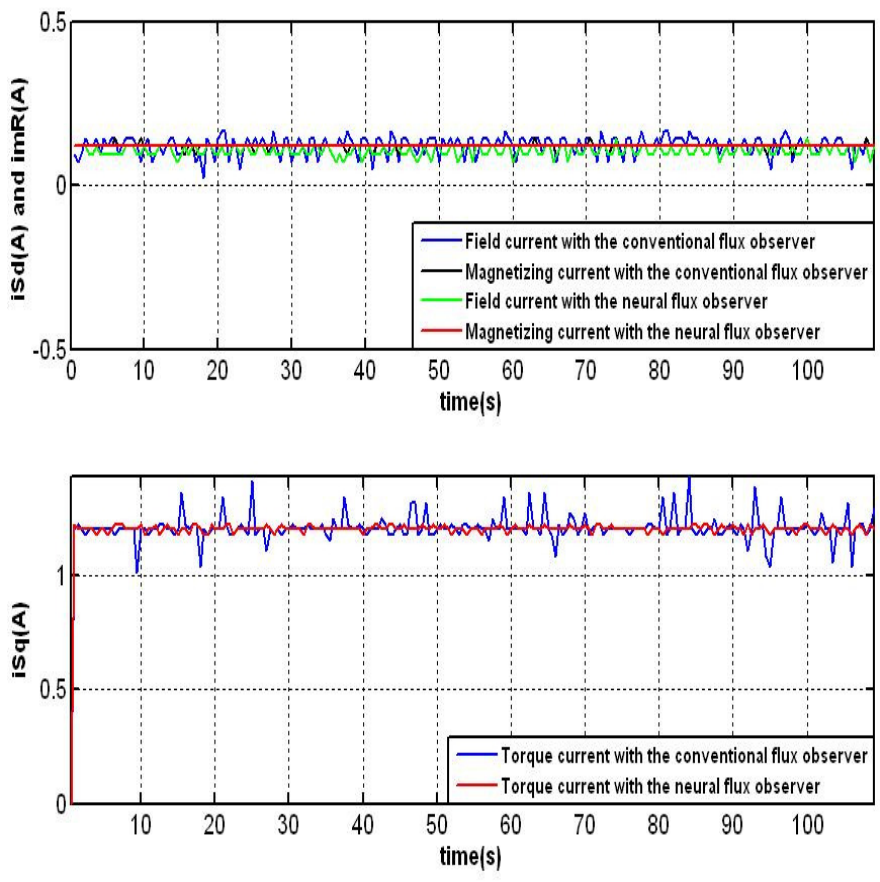

Fig. 10. Field current $\left(i_{S d}\right)$, magnetization current $\left(i_{m R}\right)$ and torque current for the ramp input.

The diagram shown in Figure 11 confirms the smooth behavior and smaller error of the stationary state of radial positioning for the system guided by the neural observer.

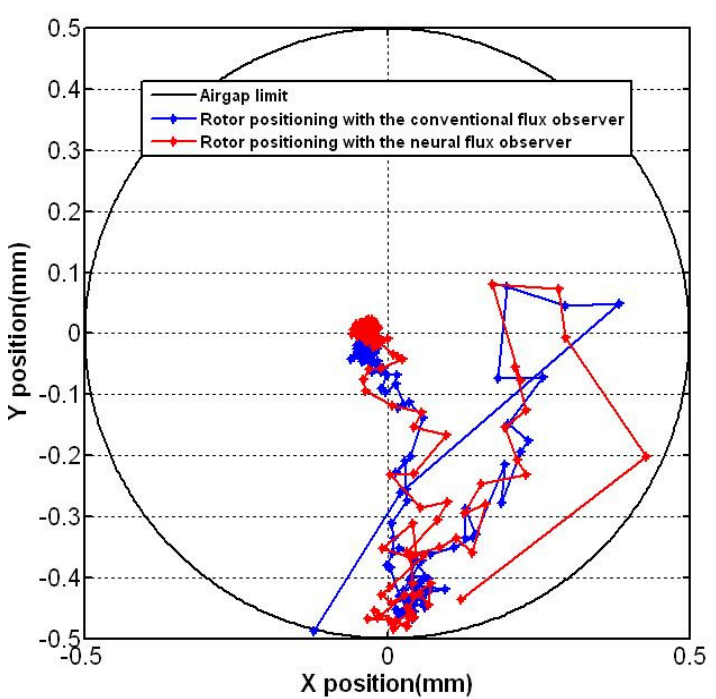

Fig. 11. Diagram of radial positioning with the neural flux observer for the ramp input.

\section{Disturbance Response}

Several tests with smooth ramps as a reference and instant load application were conducted to observe the behavior of the system under different conditions.

The responses to mechanical speed and to the $\mathrm{X}-\mathrm{Y}$ position shown in Figure 12 demonstrate that the instant load application for the system guided by the neural observer was very similar for the load applied during the operation with the conventional observer.
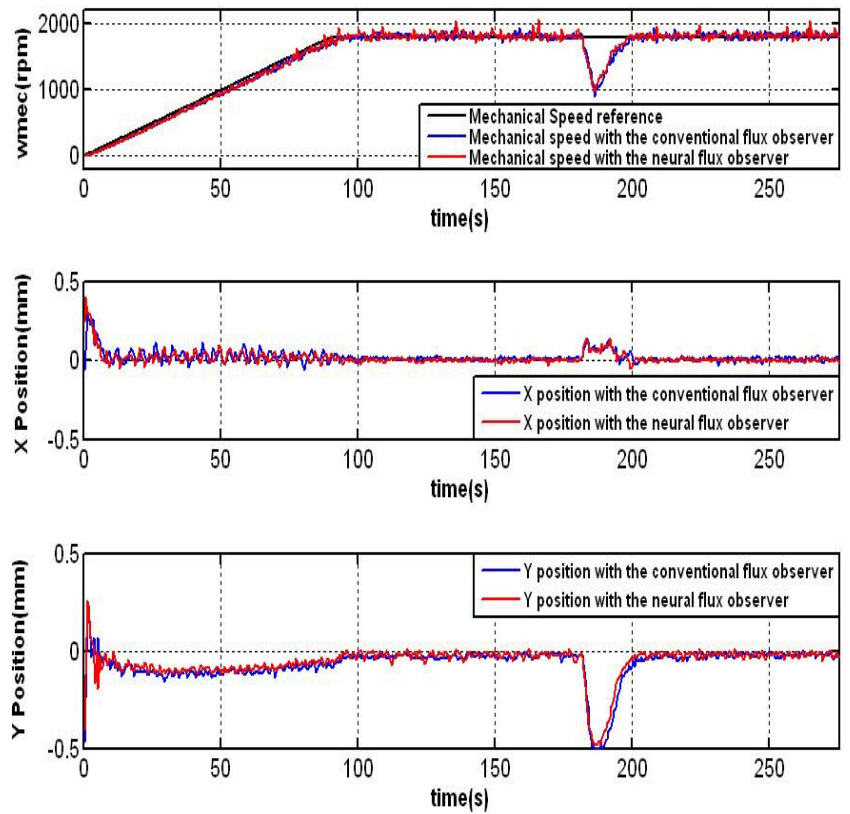

Fig. 12. Response to mechanical speed ramp and positions $\mathrm{X}$ and $\mathrm{Y}$ submitted to an instant load.

The current components $i_{S d}$ and $i_{S q}$ shown in Figure 10 loaded instantly for the system guided by the neural observer were very close to the load applied during the operation of the conventional observer.

The mechanical speed graphs $\omega_{\text {mec }}$ presented in Figure 12 show that the speed returns to the stationary state a little faster when the system is guided by the neural observer. 
For radial positioning, it is observed that during the operation with the neural observer, responses $\mathrm{X}$ and $\mathrm{Y}$ follow reference $X_{\text {ref }}=0 \mathrm{~mm}$ and $Y_{\text {ref }}=0$ with a smaller error than that of the system operating with the conventional observer for the same load conditions.

The currents $i_{S d}$ and $i_{S q}$ presented in Figure 13 show a similar behavior to that already seen in prior test (Figures 7 and 10), where the conventional observer generated oscillatory responses.
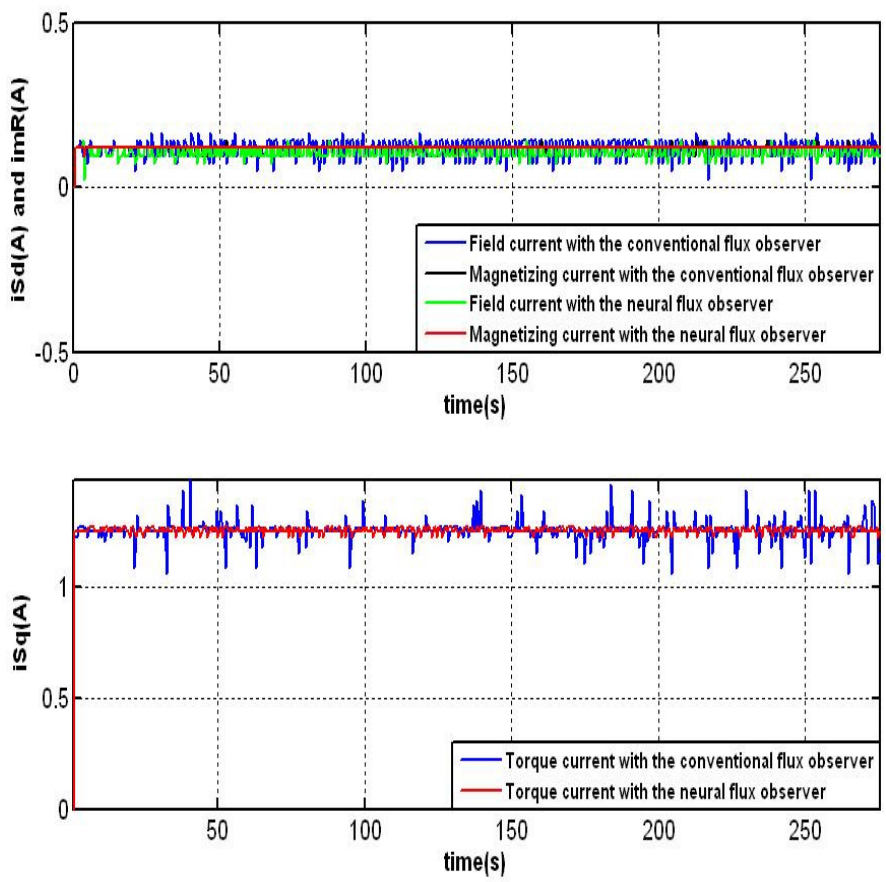

Fig. 13. Field current $\left(i_{S d}\right)$, magnetization current $\left(i_{m R}\right)$ and torque current $\left(i_{S d}\right)$ for the ramp input submitted to instant load.

The $\mathrm{Y}$ responses are the most affected by the load application for both operator observations. However, the return of the operation with the neural observer to the stationary state is faster than the response supplied by the system guided by the conventional observer.

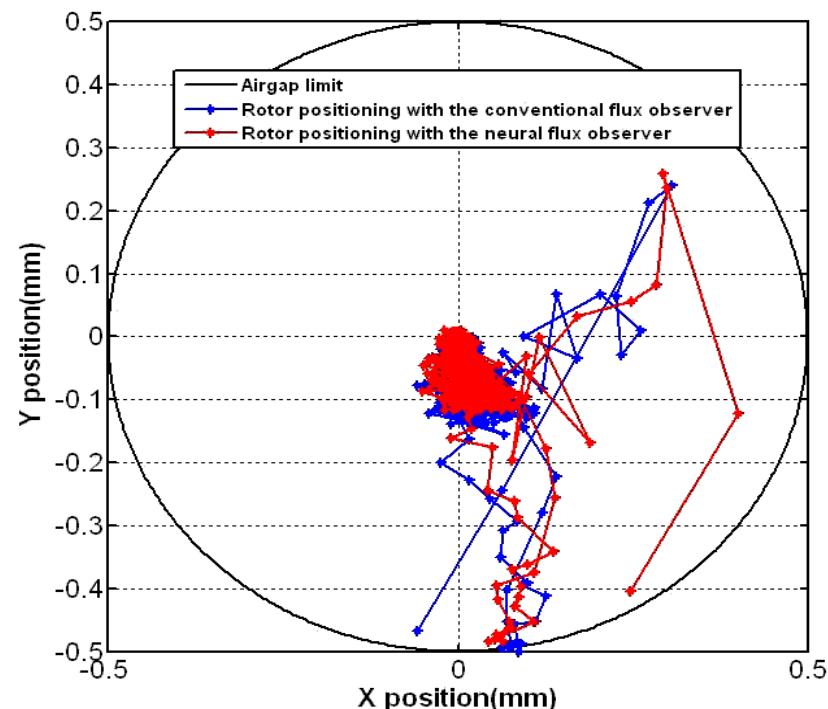

Fig. 14. Diagrams of radial positioning with the conventional and neural flux observer for the ramp submitted to instant load change.
In the radial positioning diagrams presented in Figure 14, it is observed that, despite the deterioration of responses $\mathrm{X}$ and $\mathrm{Y}$ owing to instant load application, the central line of the rotor axis remains close to reference position $X_{\text {ref }}=0 \mathrm{~mm}$ and $Y_{r e f}=0 \mathrm{~mm}$ when the system is guided by the neural observer.

The results confirm that speed control behavior guided by both observers is very similar. However, the neural observer significantly improved radial positioning control performance.

\section{CONCLUSION}

In the motor with divided windings, rotor positioning and torque production must be achieved by currents flowing through the same three-phase windings. The experimental results of this article show that the neural network of the flux observer provides precise knowledge of the system. Consequently, positioning can be accomplished more easily.

Better results are expected with the motor operating in the vertical position, especially in relation to the speed time response combined with the minimization of the oscillations during the radial positioning control. In this case, an independent axial bearing will support the weight of the motor and the currents of the motor winding can be used only for torque production and for small radial positioning efforts.

\section{ACKNOWLEDGMENT}

The authors would to thanks CAPES and CNPq for financial support.

\section{REFERENCES}

[1] A. O. Salazar, W. Dunford, R. M. Stephan, E. Watanabe, "A magnetic bearing system using capacitive sensors for position measurement" IEEE Trans. On Magnetics, Vol. 29, N 6, pp. 2941-2967, September, 1990.

[2] A. O. Salazar, R. M. Stephan, "A bearingless method for induction machine", IEEE Trans. On Magnetics, Vol. 29, No 6, pp. 2965-2967, November, 1993.

[3] A. Chiba, K. Chida, and T. Fukao, "Principle and characteristic of a reluctance motor with windings of magnetic bearing", IPEC, Japan, pp.919-926, Apr. 1990.

[4] H. Zhu, Q. Cheng, "Bearingless motor's radial suspension force control based on flux equivalent with virtual winding current analysis method" Chinese Science Bulletin, China, Vol. 54, N 9, May, 2009.

[5] J. Huang, M. Kang, J. Yang, "Analysis of a new 5phase bearingless induction motor" Journal of Zhejiang University SCIENCE, Vol. 8; $\mathrm{N}^{\mathrm{o}} 8$, pp 13111319, 2007.

[6] L. K. Wilmar, F. B. D. Domingos, A. C. D. N. Gomes, M. S. Richard, "Controle RQL de um Motor Mancal Magnético", XVIII Congresso Brasileiro de Automática, 14 a 17 setembro, Juiz de Fora/MG, 2008.

[7] T. Gempp and R. Schob, "Desing of a beringless canned motor pump" Fifth Int. Symposium of Magnetic 
Bearings, pp 333-338, Kanazawa, Japan, 1996.

[8] F.E.F Castro, "Threephase Incuction Bearingless Motor with Divided Winding: Optimization of the Radial Position System" - Master's Tese, Natal, 2004.

[9] J. M. S. Ferreira, M. Zucca, A. O. Salazar and L. Donadio, "Analysis of a Bearingless Machine With Divided Windings" IEEE Transactions on Magnetics, USA, v. 41, n 10, p. 3931-3933, 2005.

[10] J. M. S. Ferreira, A. O. Salazar, "Máquina de Indução sem Mancais: Modelo e Acionamento", Eletrônica de Potência - Vol. 12, n 3, November, pp.217-222, 2007.

[11] A. Chiba, T. Fukao, "Optimal design of rotor circuits in induction type bearingless motors", IEEE Transactions on Magnetics, Vol. 34, № 4, 1998.

[12] W. Leonhard, "Control of electrical drives", SpringerVerlag, Third Edition, Berlin Heidelberg New York, Germany, 2001.

[13] J. A. Santisteban and R. M. Stephan, "Vector Control Methods for Induction Machines: An Overview", IEEE Trans on Edu., Vol. 44, № 2, pp. 170 -175, May 2001.

[14] Paiva, J. A. "Controle vetorial de velocidade de uma máquina de indução sem mancais trifásica com rotor bobinado dividido utilizando estimação neural de fluxo", Tese de Doutorado, PPGEE - UFRN, NatalRN, Brasil, 2007.

[15] S. Haykin, "Rede neurais: Princípios e Prática", Tradução Paulo Martins Engel. - 2a Edição, Bookman, Porto Alegre/RS, 2001.

[16] K. S. Narendra and K. Parthasarathy, "Identification and control of dynamical systems using neural networks", IEEE Trans. on Neural Networks, (1):2-27, Mar 1990.

[17] S. M. G. Simões and B.K. Bose, "Neural network based estimation of feedback signals for vector controlled induction motor drive", IEEE Transactions on Industry Applications, 31(3):620-629, May/Jun 1995.

[18] M. G. Simões and B. K. Bose, "Neural Network Based Estimation of Feedback Signals for Vector Controlled Induction Motor Drive", IEEE Transactions on Industry Applications, Vol. 31, № 3, May/June 1995.

[19] P. Almeida, R. M. Stephan, P. J. C. Branco, W.I. Suemitsu, "Rotor Flux Angle Estimation Using Neural Networks". In: Electrimacs'99, 1999, Lisboa. Electrimacs'99, 1999. V. 1. P. I-157-I-162.

[20] C. A. Maia, P. Resende and J. L. Silvino, "A Neural Vector Control for Induction Machine”, ISIE - IEEE Int. Symp. on Ind. Electronics, 1997, pp:1265 - 1269.

[21] T. Suzuki, A. Chiba, M. A. Rahman and T. Fukao, "An Air- Gap-Flux-Oriented Vector Controller For Stable Operation Of Bearingless Induction Motors", IEEE Transactions On Industry Applications, Vol. 36, $\mathrm{N}^{\circ} 4$, Pp. 1069 - 1076, July-August 2000.

[22] J. M. S. Ferreira, F. E. Castro, J. A. Paiva and A. O. Salazar, "DSP utilization in radial positioning control of bearingless machine", ISIE - IEEE Int. Symposium. on Industrial Electronics, 1, 2003 pp:312 - 317.

[23] A. O. Salazar, J. M. S. Ferreira , J. A. Paiva and A. L. Maitelli, F. E. F. Castro, "New Approach for a Bearingless Three phase Induction Machine with Divided Winding." Ninth International Symposium of
Magnetic Bearings, 2004, Kentuky, 2004.

[24] W. Leonhard, "30 years space vectors, 20 years field orientation, 10 years digital signal processing with controlled AC drives". EPE-Journal, pp.13-19, 1991.

[25] S. D. Lisboa, J. A. Paiva, F. C. H. Queiroz, A. O. Salazar, A. L. Maitelli, "Neural Flux Estimation Applied to The Vector Speed Control For Induction Machines", $9^{\circ}$ Congresso Brasileiro de Eletrônica de Potência", September 30 to October 04, Blumenau/SC, 2007.

[26] Spectrum Digital, "EzDsp LF2812 Technical Reference”, DSP develop. Systems, September, 2003.

\section{BIOGRAPHIES}

José Álvaro de Paiva, is 36 years old, was born in Natal, Rio Grande do Norte, Brazil. He is graduated by the Federal University of Rio Grande do Norte since 1996, where also obtained the following titles: specialist in automation of industrial processes (1998), Master in Electric Engineering and Doctor in Electric Engineering (2007).His researches are concentrated on the industrial system control. He is teacher of the Federal Institute of Education, Science and Technology of Rio Grande do Norte since 1998 where teaches contents of Hardware, Electricity and Electronic Circuits. Nowadays, he is developing researches in the system of petroleum leaks detection on the Automation Laboratory.

Valcí Ferreira Victor, is 41 years old, was born in Santa Cruz, Rio Grande do Norte, Brazil. He is graduated by the Federal University of Rio Grande do Norte since 2000, where also obtained the title of Master in Electric Engineering and is currently a doctoral candidate in electrical engineering. His researches are concentrated on the bearingless machine. Nowadays, he is teacher of the Federal Institute of Education, Science and Technology of Tocantins since 2005.

Andres Ortiz Salazar, was born Lima, Peru, in 1956. He received the B. S. in electronic engineering from the UNIPeru and M. Eng. and DSc. degrees from COPPE-UFRJ in 1989 and 1994, respectively. He is presently a Professor in the Department of Electrical Engineering and the Department of Computer and Automation Engineering of the Federal University of Rio Grande do Norte, since 1994. He accomplished postdoctoral in the Science University of Tokyo - Japan. His research interests include power electronics, electrical machine of activate and automation and control of systems.

André Laurindo Maitelli, was born in Bento Gonçalves, $\mathrm{RS}$, Brazil, in 1965. He received the M. Eng. degree in Electrical Engineering from the University of Brasilia (UnB) in 1988 and the DSc. degree in Electronic Engineering from Aeronautics Technological Institute (ITA) in 1994. He is professor of Federal University of Rio Grande do

Norte since 1990 and currently he works in Computer and Automation Department. His research interests include theory and applications of predictive, adaptive and intelligent control systems, industrial instrumentation and measurement systems. He is currently manages many research projects applied in Petroleum Engineering. 